\title{
Retrospective Study on Incidence of Measles in Kumbotso Kano, Northern Nigeria
}

\author{
Nas FS1, Ali M2*, Yahaya A $^{3}$ and Kabiru AG $^{4}$ \\ ${ }^{1}$ Department of Biological Sciences, Bayero University Kano, Nigeria \\ ${ }^{2}$ Microbiology Department, Kano University of Science and Technology Wudil Kano, \\ Nigeria
}

\section{Research Article}

Volume 2 Issue 6

Received Date: April 30, 2018

Published Date: May 18, 2018

${ }^{3}$ Department of Biological Sciences Kano University of Science and Technology Wudil Kano, Nigeria ${ }^{4}$ School of Nursing Madobi Kano, Nigeria

*Corresponding author: Muhammad Ali, Microbiology Department, Kano University of Science and Technology Wudil Kano, Nigeria, Email: alimuhd4real@gmail.com

\begin{abstract}
Measles still remains endemic causing high morbidity and mortality among young children in developing countries, despite the availability of a safe and effective vaccine. The research was aimed to determine the incidence of measles at four health centers in Kumbotso Local Government Area, Kano State Northern Nigeria. A retrospective study was conducted using medical records of measles cases from January to June, 2015 in four health centers in the study area. A total of 327 cases of measles were extracted, reviewed and analyzed. The results showed that more males (53\%) were infected with measles than female (47\%). Temporal distribution of the incidence showed that highest incident was recorded in the month of March with total of 31\% of the incidence and lowest in June which accounted for 09\%. The distribution of the cases based on the ages of the subjects showed that highest number of cases was recorded among subjects of between $2<4$ years of age with total of 108 subjects which accounted for $33 \%$ of the cases while least number of cases (16 cases) was reported among subjects aged between 8-10 years which accounted for 5\%. Out of the 327 subjects reviewed, only 31 (09\%) were completely immunized, but on the other hand about 64\% (208 subjects) were not immunized. Statistical analysis of the result shows no significant differences in the incidence of the cases between male and female subjects, but there is statistical difference on the incidence of measles among different ages categories and monthly distribution of the cases among the study subjects at $\mathrm{p}<0.05$.
\end{abstract}

Keywords: Immunization; Infections; Measles; Morbidity; Subjects

\section{Introduction}

Measles still remains a major health problem in the tropics and subtropics despite the availability of potent vaccines; it is estimated that measles was responsible for 122,000 deaths globally in 2012 and most of these occurred in children, mostly less than 5-year olds, and in developing countries [1]. Measles is a highly infectious 
viral disease caused by a virus that belongs to the group of Morbilliviruses of the family Paramyxoviridae Transmission is through aerosol droplets or direct contact with the nasal and oral secretions of an infected person to susceptible individuals, especially children between the ages of 9 months to 15 years [2,3]. This disease is considered endemic especially in the developing countries with a peak of transmission from October to March. Measles carries with it high morbidity and mortality especially when clinical cases are not properly managed [3]. However, about 1 billion doses of the measles vaccine has been administered to children since 2000 globally but cases are still recorded in children who were vaccinated, and this is often attributed to poor maintenance of the cold chain, decreasing herd immunity, and possibly wild virus strain [1]. The virus infects the mucous membranes of exposed individual and then spreads to other part of the body. Measles is known to infect only human with no known animal reservoir Measles has an incubation period of about 10 days (with a range of 7 to 18 days) [4,5]. It is characterized by prodromal fever, conjunctivitis, coryza, cough and presence of Koplik spots. A characteristic maculopapular rash appears on the third to seventh day beginning on the face and become more generalized [6].

In developing countries, up to $75 \%$ of cases may have one or more complications [7]. The case fatality rate of measles in the developing countries is around 3-5\%; this could be as high as $10 \%$ during epidemics $[4,6,7]$. Globally, measles mortality fell $60 \%$ from an estimated 873,000 deaths in 1999 to 345,000 in 2005 [7]. The mortality rate for measles infection in children is usually $0.2 \%$, but may be up to $10 \%$ in malnourished children [8]. In cases with complications, the mortality rate may rise to $20-30 \%$ [7]. Measles affects up to 20 million people a year worldwide, most of these infections are seen in the developing areas of Africa and Asia [4,9]. Among the childhood vaccine-preventable diseases, measles causes the most deaths in children. Measles is an endemic disease in Nigeria, with recurrent outbreaks occurring at irregular intervals. Measles transmission in Nigeria occurs through all months of the year, but peaks in the dry season (February, March and April) [6]. Measles transmission also sometimes occurs immediately after the end of the rainy season and often reaches epidemic proportions in the dry season. Nigeria is one of only ten countries in the world with vaccine coverage of less than $50 \%$ and one of nine countries in which children do not have a chance of a second measles vaccination $[10,11]$.

Nigeria is among the 45 countries that account for $94 \%$ of the deaths due to measles worldwide [4]. There was little literature in Nigeria on the population-based prevalence of measles. However, some studies from tertiary hospitals showed the prevalence of measles from pediatric admissions stands at between 1.3-5.1\% [12,13]. Furthermore, the reported CFRs for measles in Nigeria showed regional variations ranging from $1.9 \%$ to $12.4 \%$ $[12,13]$. A study conducted in a secondary health center, in Southern Nigerian, observed that measles accounted for $3.1 \%$ of all pediatric admissions in the hospital; this figure is higher than the 2.3\% reported in 1998 at a tertiary health center in the same city [14]. Nigeria is one of only ten countries in the world with vaccine coverage of less than $50 \%$ and one of nine countries in which children do not have a chance of a second measles vaccination [10]. The research was aimed to determine the incidence of measles at four health centers in Kumbotso Local Government Area, Kano State Northern Nigeria.

\section{Materials and Methods}

\section{Ethical Approval}

The study was conducted following ethical approval obtained from the Health Services Management Board, Kano State based on the consent of Ethical Committee of health department of Kumbotso Local Government Area of Kano State.

\section{Study Site}

The research was conducted at 4 different health care centers in Kumbotso Local Government Area of Kano State, Nigeria. The Local Government area was created in 1976 [15]. The Local Government area has eleven (11) wards. It has an area of $158 \mathrm{~km}^{2}$ and total population of two hundred and ninety four thousand, three hundred and ninety one $(294,391)$ residents with population density of 2,197.47 inhabitant/ $\mathrm{km} 2$ [15]. According to National population commission 2006, the populations are expected to reach to 374,200 by the year 2011. It is located at an elevation of 450 meters above sea level. Its coordinates on a map are $11^{\circ} 53^{\prime} 17^{\prime \prime} \mathrm{N}$ latitudinally and $8^{\circ}$ 30 '10"E longitudinally [16]. Major towns in the local government are Kumbotso town, Chiranci, Sheka, Danbare, Challawa, Panshekara etc. Farming remains a major occupation in the area. However many educated indigenes in the area are employed in the formal sector while others engaged in various trading activities.

\section{Study Design and Subjects}

The study was a retrospective review of cases of measles recorded between January and June 2015. Records of outpatients children aged (0-10 years) in 4 different health care centers (Chiranchi, Sheka, Dan-bare 
and Panshekara) within Kumbotso Local Government Kano State were reviewed and used for the study. Relevant information such as age, sex, immunization status and clinical presentation of the subjects for period of 6 month were retrieved and reviewed for analysis.

\section{Diagnosis}

Measles case was defined using the standard WHO clinical case definition as patient characterized with prodromal fever $\left(39^{\circ} \mathrm{C}-41^{\circ} \mathrm{C}\right)$, generalized maculopapular rash appearing on the face within week from the onset of the disease, and one of the following, coryza, croup or conjunctivitis and pathognomonic Koplik's spots on the buccal mucous membrane. A confirmed case is one that meets the clinical case definition and is epidemiologically linked to a confirmed case. The health centers served as referral centers for outpatients only in the various communities under Kumbotso Local Government Areas of Kano State. Most of the complicated cases such as Diarrhea and severe dehydration, bronchopneumonia, encephalitis, seizure, acute laryngotracheitis and convulsion were recorded and referred to either specialist or teaching hospital in Kano metropolis. Most of the patients brought to the health centers were from rural community.

\section{Statistical Analysis}

Data were determined using basic descriptive statistics such as percentages and Student t-test. The data of incidence was analyzed using One-Way ANOVAs for significance at 0.05 probability level using Statistical Package for Social Science (SPSS) 2010 version.

\section{Results}

The present study includes a total number of 327 measles cases recorded from 4 different health centers over a period of 6 month in Kumbotso Local Government Area. Table 1 shows that highest incidence is recorded in Panshekara ward with 91 reported cases which accounted for $28 \%$, followed by Danbare ward with 85 reported cases (26\%) while least incidence were recorded in Chiranchi 78 cases $(24 \%)$ and Sheka 73 cases which accounted for $22 \%$. Table 1 also revealed the distribution of the recorded cases based on the sex of the subjects. Out of the total of 327 subjects recorded, 173 subjects were found to be male accounting for about $53 \%$ of the incidence during the study period while 154 cases involved females which accounted for $47 \%$ of the cases.

\begin{tabular}{|c|c|c|c|}
\hline Health centers & Male cases & Female cases & Total cases (\%) \\
\hline Danbare & 44 & 41 & $85(26 \%)$ \\
\hline Sheka & 40 & 33 & $73(22 \%)$ \\
\hline Chiranchi & 41 & 37 & $78(24 \%)$ \\
\hline Panshekara & 48 & 43 & $91(28 \%)$ \\
\hline Total & $173(53 \%)$ & $154(47 \%)$ & $273(100 \%)$ \\
\hline
\end{tabular}

Table 1: Distribution of cases based on sex of the subjects in the study area.

Key: $\mathrm{n}=4$, $\mathrm{t}$ - value $=1.305$; no significant difference on the incidence of the cases among male and female subjects.

The monthly distribution of the measles cases in the study area is presented in table 2 . The result revealed that highest incidence was reported in the month of March with total of 98 cases in all the health centres, this accounted for $30 \%$ of the total cases. In the month of
April, total of 70 cases $(21 \%)$ were reported 50 cases were reported in February which accounted for $15 \%$. Least number of cases (30 cases) was recorded in June who accounted for $09 \%$.

\begin{tabular}{|c|c|c|c|c|c|}
\hline Month & Danbare & Sheka & Chiranchi & Panshekara & Total (\%) \\
\hline January & $11^{\mathrm{a}}$ & $08^{\mathrm{a}}$ & $10^{\mathrm{a}}$ & $11^{\mathrm{a}}$ & $40(12)$ \\
\hline February & $14^{\mathrm{a}}$ & $12^{\mathrm{a}}$ & $11^{\mathrm{a}}$ & $13^{\mathrm{b}}$ & $50(15)$ \\
\hline March & $23^{\mathrm{c}}$ & $21^{\mathrm{b}}$ & $25^{\mathrm{c}}$ & $29^{\mathrm{c}}$ & $98(31)$ \\
\hline April & $17^{\mathrm{b}}$ & $18^{\mathrm{b}}$ & $15^{\mathrm{b}}$ & $20^{\mathrm{b}}$ & $70(21)$ \\
\hline May & $11^{\mathrm{a}}$ & $08^{\mathrm{a}}$ & $10^{\mathrm{a}}$ & $10^{\mathrm{a}}$ & $39(12)$ \\
\hline June & $09^{\mathrm{a}}$ & $06^{\mathrm{a}}$ & $07^{\mathrm{a}}$ & $08^{\mathrm{a}}$ & $30(09)$ \\
\hline Total & 85 & 73 & 78 & 91 & $327(100)$ \\
\hline
\end{tabular}

Table 2: Monthly distribution of measles cases recorded in the study area from January to June, 2015.

Key: values having different super script on the same column are considered significantly different at probability level of 0.05 . 
The distribution of the cases based on the ages of the subjects is presented in Table 3. The information obtained showed that highest number of cases was recorded among subjects of between $2-4$ years of age with total of 108 reported cases which accounted for $33 \%$ of the cases. This is followed by subjects ranged between $0<2$ years with 96 cases (29\%), $4<6$ years with 65 cases $(20 \%), 6<$ 8 years with 42 cases (13\%) while least number of cases (16 cases) was reported among subjects aged between 8 10 years which accounted for $5 \%$.

\begin{tabular}{|c|c|c|}
\hline Age (years) & $\begin{array}{c}\text { Number of } \\
\text { cases }\end{array}$ & $\begin{array}{c}\text { Incidence percentage } \\
\text { (\%) }\end{array}$ \\
\hline $0-<2$ & 96 & 29 \\
\hline $2-<4$ & 108 & 33 \\
\hline $4-<6$ & 65 & 20 \\
\hline $6-<8$ & 42 & 13 \\
\hline $10-$ Aug & 16 & 5 \\
\hline Total & 327 & 100 \\
\hline
\end{tabular}

Table 3: Distribution of the cases based on the ages of the subjects.

Key: values having different super script on the same column are considered significantly different at probability level of $\mathrm{p}<0.05$.

The immunization status of the subjects is presented in Table 4. Available information obtained showed that most of the subjects were not immunized with measles vaccine. The number of unimmunized subjects is 208 out of 327 which accounted for $64 \%$. Only $9 \%$ of the subjects $(31$ subjects) received complete immunization while 88 subjects $(27 \%)$ were immunized partially.

\begin{tabular}{|c|c|c|}
\hline Immunization status & $\begin{array}{c}\text { Number of } \\
\text { cases }\end{array}$ & $\begin{array}{c}\text { Percentage } \\
\text { incidence (\%) }\end{array}$ \\
\hline Complete immunization & 31 & 9 \\
\hline Partial immunization & 88 & 27 \\
\hline Not immunized & 208 & 64 \\
\hline Total & 327 & 100 \\
\hline
\end{tabular}

Table 4: Immunization status of the subjects recorded in the study area.

The number and percentage of complicated cases recorded in the four centers is presented in table 5 . The result showed that 51 cases (16\%) are complicated and referred to specialist and teaching hospital in Kano metropolis. Out of the total of 327 cases recorded, 276 cases which accounted for $84 \%$ were treated within the heath centers due to less complication of the disease.

\begin{tabular}{|c|c|c|c|}
\hline $\begin{array}{c}\text { Health } \\
\text { centers }\end{array}$ & $\begin{array}{c}\text { Complicated } \\
\text { cases }\end{array}$ & $\begin{array}{c}\text { Uncomplicated } \\
\text { cases }\end{array}$ & $\begin{array}{c}\text { Total cases } \\
\text { (\%) }\end{array}$ \\
\hline Danbare & 13 & 72 & $85(26 \%)$ \\
\hline Sheka & 12 & 61 & $73(22 \%)$ \\
\hline Chiranchi & 9 & 69 & $78(24 \%)$ \\
\hline Panshekara & 17 & 74 & $91(28 \%)$ \\
\hline Total & $51(16 \%)$ & $276(84 \%)$ & $273(100 \%)$ \\
\hline
\end{tabular}

Table 5: Number and percentage of complicated cases recorded in the four centers.

\section{Discussion}

Measles is an infection affecting children has become nearly eradicated in most developed world countries by the availability of an effective vaccine but still causes considerable disease in the developing world. It still remains endemic with devastating effect and causing high morbidity and mortality among young children in developing countries, despite the availability of a safe and effective vaccine [1]. The findings of this study found that measles is one of the diseases affecting children in Kumbotso Local Government of Kano State. The result revealed that more males were infected than females. Starting from the beginning of life, sex has a major impact on outcome from a range of infectious diseases. Overall, morbidity and mortality rates are higher in males than in females throughout life [17]. The mechanisms involved for such sexual dimorphisms are multifactorial, including the endocrine and genetic effects on the immune system and physiology, as well as sex-related differences in behavior. In humans, females reportedly mount stronger humoral and cellular immune responses to infection or antigenic stimulation than do males [18]. The result of this study was in conformity with that of Oyefolu, et al. [19] who study measles morbidity and mortality trend in Lagos, Nigeria. They found that the overall number of reported cases in all the hospitals was marginally higher for males than females. In an investigation report made by Ibrahim et al. [6] on measles outbreak in Sokoto State, Northern Nigeria, it has been found that there were more males (54.2 per cent) than females (45.8 per cent) respondent. This also justifies the present study. However, the statistical analysis of the result of this study on the incidence of measles between and female subjects shows no significant different.

According to this study, the results of monthly distributions of the measles cases in the study area indicated that highest number of incidence was recorded in the month of March and April. Several studies were conducted in relation to temporal distribution of measles among children in different part of Nigeria [20,21]. 
Similar studies on Clinical findings and outcome of measles outbreak in Kano, Nigeria revealed that more incidences were recorded during the month of April. Etuk, et al. reported that most cases of measles in Calabar Southern Nigeria were reported in the month of April [21]. This is contrary to the present due to variation in climate. High incidence of measles during the month of February - April is mostly due to dry condition. According to Ibrahim et al., measles transmission in Nigeria occurs through all months of the year, but peaks in the dry season (February, March and April), but reasons were not clearly stated [20]. Measles transmission also sometimes occurs immediately after the end of the rainy season and often reaches epidemic proportions in the dry season [22].

In this study, the distribution of the cases based on the ages of the subjects showed highest number of cases was recorded among subjects of between $0<2$ and $2<4$ years. Berggren et al. stated that high incidence and fatality among young aged children is attributed to immature cell-mediated immune response of these young infants which often render them more prone to the fatal and life-threat?ening measles complications [23]. Before the introduction of measles vaccines, one-third of children in many African countries were infected in the first and second years of life, and most children were infected before they reach 5 years of age [24]. World Health Organization in 2014 estimated that measles was responsible for 122,000 deaths globally in 2012 and most of these occurred in children, mostly less than 5-year olds, and in developing countries. High cases of measles in developing countries are due to a young age at infection, poor shelter and overcrowding, underlying immune deficiency disorders due to malnutrition, vitamin A deficiency, and lack of access to medical care. Based on the findings of this study, there is statistical difference on the incidence of measles between different age categories used in this study.

The results of the present study, demonstrated that most of the infected subject were not immunized with measles vaccine in their life time. This result was in conformity with that of Aliyu on study of clinical findings and outcome of measles outbreak in Kano, Nigeria revealed that about $61 \%$ of the subjects were not immunized completely [20]. Studies done in Nigeria had shown maternal knowledge and education to be major determinants of immunization coverage in children, hence factors that prevent measles in childhood [25]. The present study also revealed that only $16 \%$ of the cases were found to be complicated and hence referred to specialist and teaching Hospitals in Kano Metropolis for better medical treatment due to low medical facilities in the study centers.

\section{Conclusion}

Measles still remains endemic causing high morbidity and mortality among young children in Nigeria. This retrospective study showed that more males were infected with measles than female. Temporal distribution of the incidence showed that highest incident was recorded in the month of March and lowest in June. The distribution of the cases based on the ages of the subjects showed that highest number of cases was recorded among subjects of between $2<4$ years of age while least number of cases was reported among subjects aged between $8-10$ years. The study pointed out that most of the subjects were not previously immunized. There is need for improvement on routine immunization, and equipping local health facilities for successful eradication of measles from the study area and Nigeria at large.

\section{References}

1. World Health Organization (WHO) (2014) Measles.

2. Rima BK and Duprex WP (2006) Morbilliviruses and human disease. J Pathol 208(2): 199-214.

3. World Health Organization (WHO) (2012) Reported measles cases and incidence rates by WHO member states 2010 and 2011.

4. WHO (2017) Measles. World Health Organization.

5. Akande TM (2007) A review of measles vaccine failure in developing countries. Niger Med Pract SAME Ventures 52: 112-116.

6. Ibrahim BS, Gana GJ, Mohammed Y, Bajoga UA, Olufemi AA, et al. (2016) Outbreak of measles in Sokoto State North-Western Nigeria, three months after a supplementary immunization campaign: An investigation report 2016. AMJ 9(9): 324-335.

7. Kabra SK, Lodha R (2013) Antibiotics for preventing complications in children with measles. Cochrane Database Syst Rev.

8. Center for Disease Control and Prevention (2017) Case definition for public health surveillance.

9. Measles-Merck Manuals Professional Edition. Pediatrics 2016. 


\section{Virology \& Immunology Journal}

10. Nigeria Demographic and Health Survey (2013) National Population Commission Federal Republic of Nigeria 1-565.

11. Schimmer B, Ihekweazu C (2006) Polio eradication and measles immunisation in Nigeria. Lancet Infect Dis 6(3): 63-65.

12. Onyiriuka AN (2011) Clinical profile of children presenting with measles in a Nigerian secondary health-care institution. J Infect Dis Immun 3(6): 112116.

13. Ogunmekan DA, Bracken P, Marshall WC (1981) A seroepidemiological study of measles infection in normal and handicapped persons in Lagos, Nigeria. J Trop Med Hyg 84(4): 175-178.

14. Saleh JE (2016) Trends of measles in Nigeria: A systematic review. Sahel Med J 19(1): 5-11.

15. National Population Commission (NPC) (2006) National Population Census result, 2006 Abuja Nigeria.

16. Mohammed S, Muhammad NM, Abdulkarim IA (2015) Ethnobotanical Survey of Medicinal Plants in Metropolitan Kano, Nigeria International Journal of Public Health Research 3(6): 345-351.

17. Lozano R, Naghavi M, Foreman K, Lim S, Shibuya K, et al. (2012) Global and regional mortality from 235 causes of death for 20 age groups in 1990 and 2010: a systematic analysis for the Global Burden of Disease Study 2010. Lancet 380(9859): 2095-2128.

18. Fish EN (2008) The X-files in immunity: sex-based differences predispose immune responses. Nat Rev Immunol 8(9): 737-744.
19. Oyefolu AO, Omilabu SA, Akinyemi KO, et al. (2001) Measles resurgence in Nigeria: a review on the attributable factors. Nige $\neg$ rian J Res Rev Scien 2: 3345.

20. Aliyu I (2016) Clinical findings and outcome of measles outbreak in an African city. Sifa Med J 3(1): 14 .

21. Etuk IS, Ekanem EE, Udo JJ (2003) Comparative analysis of measles morbidity and mortality in Calabar during the expanded programme on immunization and the national programme on immunization eras. Niger J Paed 30(3): 81-85.

22. Grigsby ME, Adetosoye JI (1973) Measles epidemiology and control in Western Nigeria. Journal of the National Medical Association 65(5): 378-385.

23. Berggren KL, Tharp M, Boyer KM (2005) Vaccineassociated wild-type measles. Pediatr Dermatol 22(2): 130-132.

24. Halsey NA, Boulos R, Mode F, Andre J, Bowman L, et al. (1895) Response to measles vaccine in Haitian infants 6 to 12 months old: influence of maternal antibodies, malnutrition, and concurrent illnesses. $\mathrm{N}$ Engl J Med 313(9): 544-549.

25. Gidado S, Nguku P, Biya O, Waziri NE, Mohammed A, et al. (2014) Determinants of routine immunization coverage in Bungudu, Zamfara State, Northern Nigeria, May 2010. Pan Afr Med J 18(1): 9. 